\title{
Predicting the outcomes of the Korean national accreditation system for higher education institutions: a method using disclosure data for outsiders
}

\author{
Don Dong-hyun Lee ${ }^{1}$ (D) . Soon-jeong $\mathrm{Cho}^{2}$ (ID
}

Received: 28 December 2020 / Revised: 25 July 2021 / Accepted: 26 July 2021 / Published online: 26 October 2021

(c) The Author(s) 2021

\begin{abstract}
For outsiders to higher education institutions (HEIs) in South Korea, predicting the outcomes of the International Education Quality Assurance System (IEQAS) — a Korean institutional accreditation system for HEIs-is challenging. The annual IEQAS accreditation has been conducted behind closed doors; the assessment process is confidential, and there is little access to the data for the public and individuals. However, many stakeholders, such as overseas applicants to Korean HEIs, may want to predict whether particular universities will pass the upcoming IEQAS. Hence, we sought an alternative method for the outsiders to predict a binary result of the IEQAS accreditation by utilizing disclosure data that the Korean government has published. To best predict the outcomes, we mapped out a threefold discrete model combining logistic regression, discriminant analysis, and neural network. We collected the information disclosed by the Ministry of Education in 2019 on 138 Korean private HEIs and then analyzed the secondary public dataset in line with the discrete method that ensures generalizability. Results showed (i) three education investment factors, and one school operations factor appeared as key predictors among the tested indices; (ii) education cost per student within education investment proved to be the most crucial element; and (iii) while leveraging the disclosed data turned out to be reliable, neural network's predictive accuracy was higher than those reported using logistic regression and discriminant analysis. By processing the publicly available disclosure data, our self-study model may effectively assist in predicting IEQAS outcomes, and it can also be used as a diagnostic, prior to accreditation, by local HEIs in other nations to check their preparedness and likelihood of success within similar contexts.
\end{abstract}

Keywords National accreditation systems · The International Education Quality Assurance System (IEQAS) · Korean higher education $\cdot$ Discrete analysis model $\cdot$ Disclosure data

\section{Introduction and motivation}

Since the early 2000s, the South Korean government has implemented diverse higher education projects to attract foreign students at the national level. For example, the Ministry of Education (MoE) introduced a Global Korea Scholarship

Soon-jeong Cho

sj.cho@smu.ac.kr

Don Dong-hyun Lee

don.lee@aut.ac.nz

1 School of Engineering, Computer \& Mathematical Sciences, Auckland University of Technology, WT704, AUT Tower, 2-14 Wakefield Street, Auckland 1142, New Zealand

2 College of Global Regions, Sangmyung University, E329, Songbaek-guan, 31 Sangmyungdae-gil, Dongnam-gu, Cheonan 31066, South Korea
Program that has encouraged higher education institutions (HEIs) to recruit overseas applicants. Subsequently, the MoE carried out a more ambitious long-term initiative, the Study Korea 2020 Project, to support successful acclimation for the new students as well as to promote employment and business start-ups for international students graduating from Korean HEIs. By extension, in a bid to ensure quality education and select high-caliber foreign students, the government developed an accreditation system, the International Education Quality Assurance System (IEQAS), for all Korean HEIs in 2012 when the number of international learners had reached 90,000 (Bae, 2015). Not only does the IEQAS examine the administrative capacity of an individual institute in managing international students, but the government-led initiative also considers competitive education courses in the institute. It is a robust institutional measure against the actions of many HEIs when "hunting for" new overseas students in 
response to a steady decline in local student numbers (Kim $\&$ Oh, 2015).

Under the IEQAS, when a Korean HEI satisfies the requirements for managing competitive foreign learners and the institute is committed to a quality program, it will be certified as an "IEQAS-accredited" school, leading to an international education qualification in Korea. While it is regarded as effective in improving the educational quality in Korea, the IEQAS is criticized for a lack of transparency in its review process (K. Ko, 2017; Paik, 2015). In compliance with IEQAS criteria (i.e., the use of tuition, the cases of illegal overstaying, education facilities, etc.), all HEIs educating foreign students are required to provide the $\mathrm{MoE}$ with closed reports. The HEIs that then seek to bi-annually acquire an accreditation must submit subsequent evidence of support for their international students and prove the up-to-date status of managing the enrolled students. By looking into the system's sub-criteria, the IEQAS panel evaluates every single HEI's competence and determines whether to either certify/recertify the school or deny/revoke certification, followed by a sanction (i.e., visa denial at the institute level) for any HEI ranked in the bottom five percent (Bae, 2015).

Within the educational circles, a wide range of groups associated with HEIs is involved in the assessment of universities and colleges (Hughes \& Barrie, 2010; Sin et al., 2017). External stakeholders contribute to funding institutions and building quality assurance frameworks in higher education (Shah, 2012). Despite the Korean MoE's positive point of view on the IEQAS, influential stakeholders and outsiders, including applicants, parents, alumni, trustees, and other schools, are frustrated by a difficulty in predicting the IEQAS results (K. Ko, 2017); the IEQAS panel's review process is carried out behind closed doors between the external agencies and the MoE teams. Moreover, the acquisition of evaluation data on IEQAS is limited to the general public, and the detailed results by IEQAS criterion have not been publicized. Many scholars argue that an alternative method using publicly open data should be developed so that outsiders on an individual level can efficiently predict whether a specific HEI stays an IEQAS-accredited school (Kim \& Lee, 2017; Oh \& Park, 2018; Sohn, 2013). To address these challenges and needs, our study proposes an informal self-study whereby we can predict, to some extent, the outcomes of IEQAS accreditation using published data. In response to a national accreditation process, each institute's self-study is "the most valuable part of the accreditation process," and a simple self-reflection of this type is useful "to identify areas of needed improvement and to set forth plans of action" for campus planning (Wolff, 1993, p. 93-94).

The objective of this study seeks an alternative method for the outsiders that predicts a binary outcome of IEQAS accreditation by utilizing public disclosure data. Our work also aims to examine whether our method within the analytic model can be generalizable in predicting the results to be used as a self-study instrument for the public and individuals. Based on a threefold discrete method combining two statistical techniques and an intelligent computational skill, it includes in-depth discussions on the prediction accuracy across three analyses and identifies which input factors appear as reliable in terms of the self-study process for IEQAS accreditation. Through the lens of pragmatism, we suggest an underlying question and two sub-questions: Can the alternative method using public disclosure data provide reliable results to predict the Korean national accreditation system in higher education? (i) To what extent can this method using public data predict the outcomes of IEQAS accreditation? (ii) Which indices in the method demonstrate the most explanatory power in predicting IEQAS accreditation?

\section{Literature review}

\section{Quality assurance in higher education}

Quality assurance (QA) within the HEI context is characterized by an external locus of control in association with the central government's administrative structure and external auditors in HEIs who measure complex indicators of success in line with the guidelines and criteria (Leeh, 2015). Since the mid-2000s, many scholars and practitioners in international higher education have introduced various research with different professional views in a diverse national context. The researchers focus on their studies that report international QA trends and practices in a specific country (Ingvarson et al., 2006), analyze HEI's QA arrangements and management policies (Bae, 2015), evaluate the effectiveness and success of QA systems (Hughes \& Barrie, 2010; Shah, 2012), review the roles of a national QA and accreditation system (Oh \& Park, 2018), demonstrate a comparison in performance between QA accredited and non-accredited HEIs (Kim \& Lee, 2017), and explain the QA-related policies and the useful instruments for HEIs (K. Ko, 2017; Leeh, 2015; Paik, 2015). From the policy maker's perspective, most of their views stay on an institutional/organizational level to identify the issues of QA systems. In contrast, a small number of the studies argue the necessity of developing an auxiliary instrument that can be supplementarily used for a casual self-study to predict HEI accreditation at the individual level. When it comes to a QA framework in higher education, accreditation refers to "an endorsement by an independent external agency" (Ingvarson et al., 2006, p. 1). This means that it is an organizational preparation in an HEI to be adequate for a particular academic program and an integral mechanism for assuring the education quality at the institutional level. As such, many governments have 
developed different national QA systems for HEIs as a direct policy tool that controls their universities (K. Ko, 2017). On the other hand, other than the QA agency and the central government, we have another group of stakeholders around HEIs, such as intending students as well as their parents and independent education professionals, who may be interested in undertaking a self-evaluation individually and developing a university-level internal QA method (Leeh, 2015).

\section{Challenges of the IEQAS at the individual level}

The Korean MoE developed and implemented the IEQAS in 2011-2012 when the number of international students in Korean universities and junior colleges reached nearly 100,000 . The purpose of the new national assurance system is to enhance the brand power of South Korean HEIs by adopting a global standard to the HEIs and imprint the public in a positive image of studying within Korea (Bae, 2015). To evaluate an institution's competence for international education, the Korean government has set ten evaluation indicators in a combination of the quantitative and qualitative criteria. ${ }^{1}$ In case an HEI fails to provide the quality of foreign students and support services in accordance with the IEQAS criteria, the institutions will not be accredited by the IEQAS (K. Ko, 2017). While the IEQAS has been evaluated to positively affect the education quality of Korean HEIs, it is only usable in South Korea because the system is problematic in its generality and universality (Oh \& Park, 2018). Furthermore, the IEQAS has been criticized for many specific indicators in evaluating the management capacity of Korean HEIs, in addition to the general indicators on the HEI's education capacity. The process takes more than six months from the initial assessment to the site visit (Leeh, 2015). Most importantly, the actual indicators obtained from all HEIs are not clearly made public (Paik, 2015).

The IEQAS is a unique national quality assurance system that issues the authorized certification for solid quality control toward Korean HEIs, presenting the robust guidelines and imposing the institutional "sanctions," while other quality assurance systems in different countries primarily involve the financial rewards and supports (Leeh, 2015, p.62). In fact, after periodically screening the competence of every single HEI since 2013, the Korean MoE has imposed critical

\footnotetext{
${ }^{1}$ For the undergraduate degree programs, the IEQAS criteria include (1) the illegal residency rate; (2) the internationalization program plan and infrastructure; (3) the adequacy of student selection and admission; (4) the medical insurance subscription rate; (5) the international student tuition burden ratio; (6) the support for study and life of international students; (7) the international student counseling rate; (8) the dropout rate; (9) the certified language proficiency for international students; and (10) the satisfaction and management of international students (StudyinKorea, 2021, May 18).
}

sanctions for institutions ranked in the bottom 5\%, including the prohibition of visa issuance, and then not allowed the HEIs in question to recruit new international students (Bae, 2015). This implies that from an outsider's perspective, when selecting a university prior to the application, the overseas applicants need to forecast on their own in advance whether the shortlisted HEIs would be accredited or not. However, the challenges at the individual level are in that not only many of the unique IEQAS criteria related to each HEI's results of accreditation are unreleased to the public, but also there is no alternative instrument for a self-study that can be effectively and intuitively used for the outsiders and stakeholders around the HEIs by credible public sources and proven analytic skills (K. Ko, 2017; Leeh, 2015; Oh \& Park, 2018).

\section{Applicable discrete analytic methods}

Within the private sector, predicting the outcome of a specific firm's operations is statistically carried out by relying on public data sources. As such, in the business management context, a discrete analysis or a binary choice model is applied to predict either-or results, for example, bankruptcy or revival for an insolvent enterprise. Such a discrete model method may employ logistic regression (LR) and/ or discriminant analysis (DA) together with data from a secondary dataset. Since the 1990s, with advances in computer sciences, neural network $(\mathrm{NN})$ has also been used to improve predictive power (see Table 1). NNs are biologically inspired; an NN model is a non-linear/linear predictive model that deals with noisy data in an out-of-sample environment (Spear \& Leis, 1996). Using the multilayer perceptron (MLP) network architecture in particular, an NN approach is feasible where a theoretical hypothesis or a prior statistical assumption may not be required (IBM, 2019).

LR and DA are similar in that both methods are used to make a choice between the independent and dependent variables in two groups; however, they are also different in that LR is based on a non-linear logit function that seeks a maximum likelihood, whereas DA creates a linear discriminant function to classify a proportional chance. In predicting the probability of response, in contrast, an NN is a nonparametric approach using a learning process that can minimize the error with experimental knowledge. In the area of higher education, Galbraith et al. (2012) and Walter (2020) utilized NN-based models to forecast student achievement of learning outcomes in HEI and to see outliers in leadership attributes. While the business sector has widely used an NN-predictive application over the decades, a few scholars in higher education apply LR to predict student learning outcomes and university-based course accreditations, the Association to Advance Collegiate Schools of Business 
Table 1 Three analytic techniques applied to the discrete model in this study

\begin{tabular}{llll}
\hline Key concepts & Logistics regression & Discriminant analysis & Neural network (MLP $\left.{ }^{\mathrm{a}}\right)$ \\
\hline Prediction method & Statistical/probable & Statistical/classifying & Computational/biological \\
Knowledge acquisition & Maximum likelihood & Proportional chance & Experimental knowledge \\
Prior assumption & Logit distribution & Multivariate distribution & Optionally normalized \\
Model structure & Non-linear & Linear & Linear \\
Forms of the factors & Independent-dependent & Independent-dependent & Input-output \\
Probability predictions & Logistic function & Discriminant function & Activation function \\
Test of significance & Wald statistics $(W)$ & Wilks' Lambda $(\lambda)$ & A learning process \\
\hline
\end{tabular}

Adopted from IBM (2019)

${ }^{\text {a } M u l t i l a y e r ~ p e r c e p t r o n ~}$

${ }^{b}$ In case of using feedforward architecture
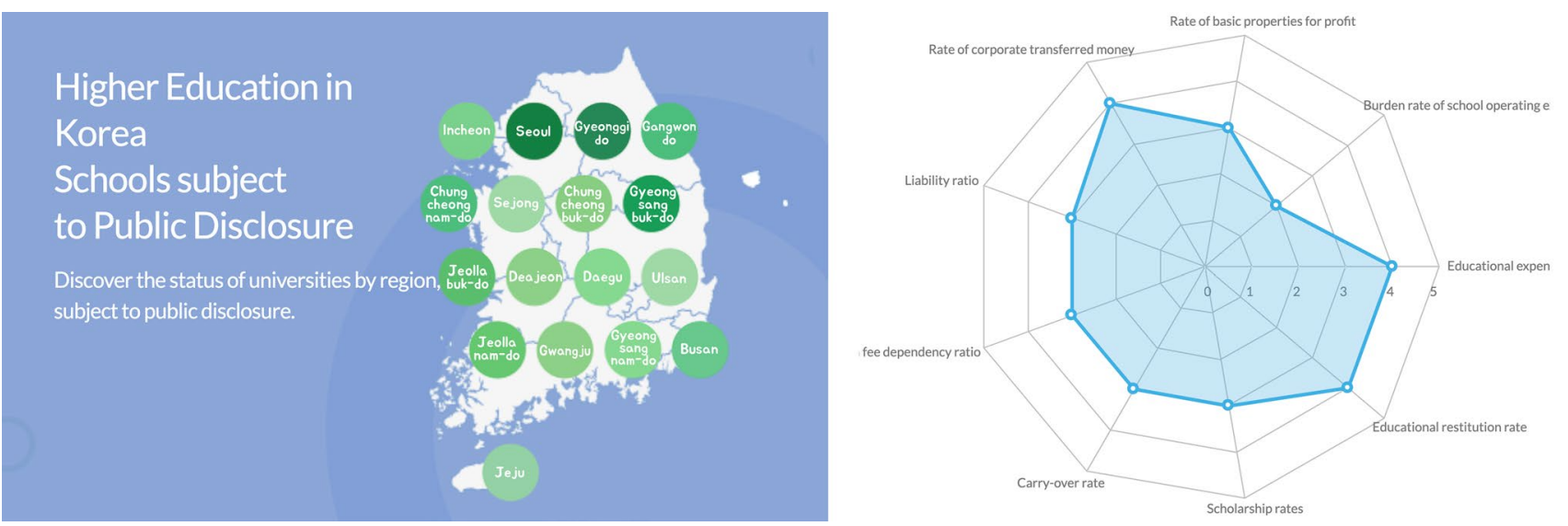

Fig. 1 The MoE's 141 private HEIs data and nine competitiveness indices in 2016-2018

(AACSB), for instance (Bitter \& Henry, 2015; Mills et al., 2012). ${ }^{2}$

In attempting a self-study for higher education accreditation, none of the prior studies has examined the usability of $\mathrm{NN}$ models incorporating the university-specific factors to minimize prediction errors. More importantly, prior HEIrelated studies that utilized binary statistical skills, such as the LR-based analysis, to forecast the outcomes of diverse national accreditations showed the overall prediction/classification error rates ranging from $28 \sim 35 \%$ to $33 \% \sim 41 \%$ (Choi \& Moon, 2017). The literature reports the reasons for the error rates shown in its study: (i) the variables represent a strong non-linear dynamic, and (ii) traditional statistical

\footnotetext{
2 The AACSB is an American professional organization as a premier accrediting agency that grants national accreditation for business management courses in international HEIs and business schools (Sohn, 2013). Therefore, the IEQAS and the AACSB do not belong to the same category. However, please note that these researchers reviewed the AACSB-related literature to refer to how the studies on the AACSB utilized external data and analytic techniques in predicting the academic outcomes and the AACSB accreditations.
}

methods may be ineffective for binary choice models within the empirical studies. In that sense, by imposing minimal demands on model structure and assumptions, the MLP, one of the NN procedures, is useful to employ a wide range of prediction models not requiring specific hypotheses about a relationship between input factors because the MLP procedure can produce a predictive model for multiple target variables based on the values of the posited variables.

\section{Methodology}

\section{Selection and collection of the data}

In October-November 2019 and February 2020, we gathered data from two credible online sources on Korean HEIs where the MoE has managed the public data since 2016: the official website of Academy Information (academyinfo.go.kr) and Study in Korea (studyinkorea.go.kr). Specifically, in October 2019, the Korean Ministry disclosed the unformatted data on 141 private HEIs over the internet. On the MoE website of My University "competitiveness" in Academy 


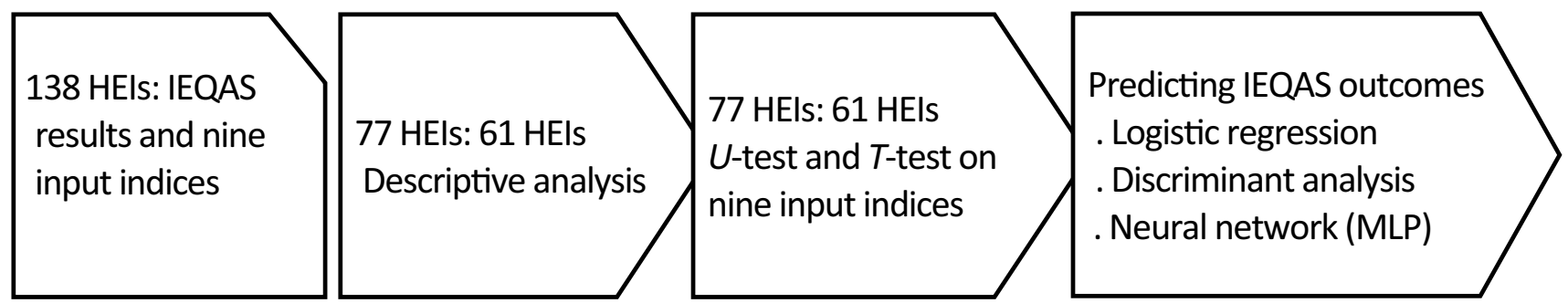

Fig. 2 Manipulation of the 138 private HEIs using the MoE's disclosed data (2016-2018)

Information shown in Fig. 1, we selected nine indices from the disclosed data available on 138 institutes, ranging from finance accounting indices to school operation indices in which data were accumulated for three consecutive years in 2016-2018. ${ }^{3}$ As most possible substitutes in developing an alternative to quality assurance, these indices are suitable to be used for analytic methods in a bid for a self-evaluation (Oh, 2016). We then collected the 2018 IEQAS outcomes for 138 HEIs from the Study in Korea, excluding three HEIs that the Korean government had ordered to close as substandard institutes in different HEI standards.

As a result, we were able to identify 77 accredited (hereinafter, ACC) IEQAS institutes coded as (0) and 61 nonaccredited (hereinafter, NAC) IEQAS institutes marked as (1), respectively. According to studyinkorea.go.kr, there are four cases of the outcome within the IEQAS assessment: an accredited (successful) or not accredited (not successful) HEI that applied for the IEQAS qualification for the first time, and a re-accredited (successful) or dis-accredited (not successful) HEI that applied for a renewal of the qualification two years after its initial IEQAS acquisition. Based on such an "either-or" result (i.e., successful or not successful) that the Korean MoE announces the IEQAS results bi-annually, this study re-arranged and simplified them as accredited [ARC, (0)] and non-accredited [NAC, (1)] for the IEQAS by categorizing four outcomes in the two settings.

\section{Analysis of the data}

As previously stated, for the casual self-study that predicted the outcomes of IEQAS accreditation, we set out a threefold

\footnotetext{
${ }^{3}$ In a different menu of My University in Academy Information, there were also another five indicators showing 141 HEI's operating status (e.g., the acceptance rate of new students, the employment rate of graduates, etc.). However, the indicators contained merely a year's information presented in 2018 within a different scale that was different from the nine competitiveness indices. To keep consistency in analyzing data using the same analytic skills, the authors and their research mentors, therefore, concluded that this study should utilize the selected nine competitive indices only not to impair the validity and reliability of the research model.
}

discrete analysis process using LR, DA, and the MLP (see Fig. 2). Selecting LR and the MLP in the analytic process is reasonable because DA needs more samples (in addition to $138 \mathrm{HEIs}$ ) to be an ideal sample size that converges linearly to a standard normal distribution in accordance with Cochran's formula (1977). This approach can compensate for the shortcomings of only using DA. Prior to the combined analyses to predict IEQAS outcomes, we first produced descriptive statistics on all 138 HEIs selected for this study. We also ran a non-parametric test ( $U$ test) and a parametric test ( $T$ test) to compare means for nine competitiveness indices between two groups-77 ACC HEIs and 61 NAC HEIs.

Using this evidence, we then attempted to identify each pivotal index that might significantly affect the desired prediction. Next, we applied two statistical methods and an $\mathrm{NN}$ approach to the significant indices, predicting a binary outcome of IEQAS accreditation. Finally, we evaluated the analytic model by reviewing the predictive accuracy across three outputs in a synthesized table. In using the analytic software, we chose two computer applications: MS-Excel 365 , a spreadsheet program for coding unformatted text data and conducting descriptive analysis as well as IBM SPSS Statistics 26, a quantitative data analyzer, for executing LR, DA, and the MLP.

\section{Structure of the variables}

As Table 2 shows, the posited independent variables (the input layers in the case of NN-MLP) from the MoE's disclosure data include nine input indices (hereinafter, predictors) in two categories, education investment and school operations, that are scaled in ordinals that the MoE defined as the fiscal year (FY) 2016-2018 competitiveness index published in 2019. Within the education investment variables, we have (a) education cost per student in South Korean won (ECOS); (b) net tuition dependency ratio (NTDR); (c) tuition for education services (STES); (d) tuition for offering scholarship (STOS); and (e) funding from the foundation (SFFD). Within the variables of school operations, there are (a) carry-over ratio (COVR); (b) total debt-to-equity ratio 
Table 2 Variables/layers used for this self-study on the IEQAS accreditation

\begin{tabular}{|c|c|c|c|c|c|}
\hline \multicolumn{2}{|l|}{ Variable } & $\begin{array}{l}\text { Input } \\
\text { index }\end{array}$ & Attribute & $\begin{array}{l}\text { Published year (Data } \\
\text { as of) }\end{array}$ & Data source \\
\hline \multirow[t]{2}{*}{ Independent $^{\mathrm{a}}$} & Education investment (EIV) & $\begin{array}{l}\text { EDCS } \\
\text { NTDR } \\
\text { STES } \\
\text { STOS } \\
\text { SFFD }\end{array}$ & $\begin{array}{l}\text { Competitiveness index } \\
\text { (ordinal) }\end{array}$ & 2019 (FY2016-2018) & academyinfo.go.kr \\
\hline & School operations (SOP) & $\begin{array}{l}\text { COVR } \\
\text { TDER } \\
\text { SPRM } \\
\text { SOEX }\end{array}$ & & & \\
\hline Dependent $^{\mathrm{a}}$ & IEQAS & & Binary value (nominal) & 2019 (FY2018) & studyinkorea.go.kr \\
\hline ECOS & Education cost per student & & COVR & Carry-over ratio & \\
\hline NTDR & Net tuition dependency ratio & & TDER & Total debt-to-equity rat & \\
\hline STES & Tuition for education services & & SPRM & Property for revenue- $\mathrm{m}$ & aking \\
\hline STOS & Tuition for offering scholarship & & SOEX & Operating expenditure & \\
\hline SFFD & Funding from the foundation & & IEQAS & accredited (0)Inon-accr & edited (1) \\
\hline
\end{tabular}

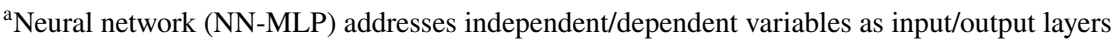

(TDER); (c) property for revenue-making (SPRM); and (d) operating expenditure (SOEX). The nine predictors are not parts of the IEQAS assessment indices but are used by multiple studies on the HEI quality evaluation as the Korean MoE's public datasets have been field-proven. Lastly, the dependent variable (the output layer for NN-MLP) owns a binary code to be either (0) or (1) in line with the IEQAS result, as of FY2018, announced in February 2019.

\section{Results}

\section{Descriptive analysis}

As empirical research, we reviewed the published data of 138 HEIs in two classes, comparing different key items in descriptive statistics between the ACC institutes $(n=77)$ and the NAC institutes $(n=61)$. As Table 3 shows, we can see remarkable contrasts between the two HEI groups. In terms of geographical region, $49.4 \%(27.3 \%+22.1 \%)$ of the ACC HEIs are in the capital territory (Seoul and its satellite towns) and six metropolitan cities in Korea. In contrast, $31.1 \%(16.3 \%+14.8 \%)$ of the NAC institutes are based in seven megapolis regions. Therefore, more than two-thirds of the NAC HEIs are in small/medium-sized cities of the provincial regions. In regard to when the HEIs were found, the ACC institutes largely have relatively long histories. Also, $37(19+18)$ out of $77(48.1 \%)$ ACC HEIs are over 50 years old, whereas only $17(5+12)$ out of $61(27.9 \%)$ NAC HEIs have a 50-year history; 36 NAC institutes $(25+11)$ are even less than 30 years old. Such a difference is obvious in the number of departments as well. In the ACC HEIs, there are 11 schools (14.3\%) that have fewer than 50 departments; however, $59 \%$ of NAC HEIs (36) have under 50 departments. As for the number of foreign students, 37 ACC HEIs $(8+29$,

Table 3 Descriptive statistics for the 138 private institutes in two HEI groups

\begin{tabular}{|c|c|c|c|c|}
\hline \multicolumn{2}{|c|}{ Accredited $(n=77)$} & \multirow[t]{2}{*}{ Demographic categories } & \multicolumn{2}{|c|}{$\begin{array}{l}\text { Non-accredited } \\
(n=61)\end{array}$} \\
\hline Number & Share $(\%)$ & & Number & Share $(\%)$ \\
\hline & & Geographical region & & \\
\hline 21 & 27.3 & Capital territory & 10 & 16.3 \\
\hline 17 & 22.1 & Metropolitans & 9 & 14.8 \\
\hline \multirow[t]{2}{*}{39} & 50.6 & Provincial cities & 42 & 68.9 \\
\hline & & Year established & & \\
\hline 19 & 24.7 & Before 1950 & 5 & 8.2 \\
\hline 18 & 23.4 & $1950 \sim 1970$ & 12 & 19.7 \\
\hline 14 & 18.2 & $1971 \sim 1990$ & 8 & 13.1 \\
\hline 19 & 24.7 & $1991 \sim 2000$ & 25 & 41.0 \\
\hline \multirow[t]{2}{*}{7} & 9.1 & $2001 \sim 2020$ & 11 & 18.0 \\
\hline & & Number of departments & & \\
\hline 11 & 14.3 & Less than 50 & 36 & 59.0 \\
\hline 25 & 32.5 & $50 \sim 100$ & 14 & 23.0 \\
\hline 21 & 27.3 & $101 \sim 150$ & 3 & 4.9 \\
\hline 13 & 16.9 & $151 \sim 200$ & 6 & 9.8 \\
\hline \multirow[t]{2}{*}{7} & 9.1 & Greater than 200 & 2 & 3.3 \\
\hline & & $\begin{array}{l}\text { Number of foreign } \\
\text { students }\end{array}$ & & \\
\hline 8 & 10.4 & Less than 100 & 35 & 57.4 \\
\hline 29 & 37.7 & $100 \sim 500$ & 21 & 34.4 \\
\hline 19 & 24.7 & $501 \sim 1000$ & 4 & 6.6 \\
\hline 13 & 16.9 & $1001 \sim 2000$ & 0 & - \\
\hline 6 & 7.8 & $2001 \sim 4000$ & 1 & 1.6 \\
\hline 2 & 2.6 & Greater than 4000 & 0 & - \\
\hline
\end{tabular}


Table $4 U$ test: Differences in input indices between two HEI groups

Table $5 T$ test: Differences in input indices between two HEI groups

\begin{tabular}{|c|c|c|c|c|c|c|c|}
\hline \multirow[t]{2}{*}{ Input factors } & \multicolumn{2}{|c|}{ Total $(N=138)$} & \multirow{2}{*}{$\begin{array}{l}\text { Accredited } \\
\text { Mean rank }\end{array}$} & \multirow[t]{2}{*}{ Non-accredited } & \multirow[t]{2}{*}{$Z$-value } & \multirow[t]{2}{*}{ Mann-Whitney } & \multirow[t]{2}{*}{$p$-value } \\
\hline & M & SD & & & & & \\
\hline \multicolumn{8}{|l|}{ (EIV) } \\
\hline EDCS & 3.0241 & 1.04782 & 78.50 & 58.14 & -3.024 & 1655.5 & $0.002 * *$ \\
\hline NTDR & 3.0219 & 0.97951 & 72.41 & 65.83 & -0.970 & 2124.5 & 0.332 \\
\hline STES & 3.0192 & 1.04778 & 76.95 & 60.10 & -2.490 & 1755.0 & $0.013^{*}$ \\
\hline STOS & 3.0411 & 0.97647 & 66.10 & 73.79 & -1.134 & 2087.0 & 0.257 \\
\hline SFFD & 3.0457 & 1.02713 & 65.68 & 74.32 & -1.683 & 2194.5 & $0.040^{*}$ \\
\hline \multicolumn{8}{|l|}{ (SOP) } \\
\hline COVR & 3.0290 & 0.97953 & 69.92 & 68.98 & -0.138 & 2316.5 & 0.890 \\
\hline TDER & 2.9116 & 0.99320 & 73.08 & 63.77 & -1.892 & 1904.0 & $0.037 *$ \\
\hline SPRM & 3.1196 & 1.20075 & 68.51 & 70.75 & -0.343 & 2272.5 & 0.732 \\
\hline SOEX & 4.3891 & 1.05864 & 71.77 & 66.64 & -0.839 & 2174.0 & 0.402 \\
\hline
\end{tabular}

Bold values are significant at conventional levels

$* p<0.05$

$* * p<0.01$

\begin{tabular}{|c|c|c|c|c|c|c|}
\hline \multirow[t]{2}{*}{ Input factors } & \multicolumn{2}{|c|}{ Accredited $(n=77)$} & \multicolumn{2}{|c|}{ non-accredited $(n=61)$} & \multirow[t]{2}{*}{$t$-value } & \multirow[t]{2}{*}{$p$-value } \\
\hline & $\mathrm{M}$ & SD & M & SD & & \\
\hline \multicolumn{7}{|l|}{ (EIV) } \\
\hline EDCS & 3.249 & 0.965 & 2.743 & 1.088 & 2.88 & $0.005 * *$ \\
\hline NTDR & 3.030 & 0.833 & 3.027 & 1.146 & 0.17 & 0.986 \\
\hline STES & 3.225 & 0.879 & 2.760 & 1.185 & 2.65 & $0.009 * *$ \\
\hline STOS & 3.087 & 0.861 & 2.940 & 1.114 & 0.87 & 0.385 \\
\hline SFFD & 2.940 & 0.934 & 3.170 & 1.021 & -1.39 & $0.039 *$ \\
\hline \multicolumn{7}{|l|}{ (SOP) } \\
\hline COVR & 2.832 & 0.793 & 2.786 & 1.006 & 0.29 & 0.769 \\
\hline TDER & 2.943 & 0.816 & 3.175 & 1.239 & -1.36 & $0.047 *$ \\
\hline SPRM & 3.061 & 1.168 & 3.194 & 1.246 & -0.65 & 0.519 \\
\hline SOEX & 4.481 & 0.947 & 4.273 & 1.183 & 1.14 & 0.082 \\
\hline
\end{tabular}

Bold values are significant at conventional levels

$* p<0.05$

$* * p<0.01$

48.1\%) have fewer than 500, and 21 schools in the group have more than 1000 students from overseas. On the other hand, 56 NAC HEIs $(35+21,91.8 \%)$ do not exceed 500 in the number of international students, and only one institute has $1000+$ enrolled foreign students in the NAC HEI group. Thus, it is demonstrated that the IEQAS-accredited institutes show a tendency to maintain more departments as well as foreign students and have a longer history than the non-accredited HEIs.

\section{Means comparison}

Next, to look into the significant differences in value between two HEI groups, we conducted a non-parametric test (Mann-Whitney $U$ test) followed by a parametric test
( $T$ test) because the sample data might not be normally distributed in nature. Tables 4 and 5 demonstrate the results presenting the differences in mean $(M)$ and the standard deviation $(S D)$ between the independent variables (for $\mathrm{NN}$ MLP: input layers), which are mutually exclusive.

From both the tests comparing the means, we can identify that four underlined factors, including EDCS, STES, SFFD, and TDER, are significant at conventional levels. Specifically, while EDCS is significantly different at $p<0.01$ on a Mann-Whitney $U$ test, the mean in EDCS of ACC HEIs is 3.249; however, the value for NAC HEIs shows 2.743 during the parametric test. In the case of STES as well as SFFD, each mean value for ACC HEIs appears as 3.225 and 2.939, whereas the mean values for NAC HEIs stay at 2.760 and 3.169, showing a distinct difference in $T$ test between the 
Table 6 Model summary-Logistic regression

\begin{tabular}{lllll}
\hline $\begin{array}{l}-2 \text { log-likeli- } \\
\text { hood }\end{array}$ & Nagelkerke $R^{2}$ & Chi-square & $\begin{array}{l}\text { Degree of } \\
\text { freedom }\end{array}$ & $p$-value \\
\hline 164.674 & 0.220 & 24.775 & 4 & 0.000 \\
\hline
\end{tabular}

Table 7 Variables in the equation-Logistic regression

\begin{tabular}{lclcll}
\hline Input factor & Coefficient & $\begin{array}{l}\text { Standard } \\
\text { error }\end{array}$ & Wald & $p$-value & Odds ratio \\
\hline (EIV) & & & & & \\
EDCS & -0.584 & 0.307 & 3.613 & $0.047^{*}$ & 0.558 \\
STES & -0.483 & 0.309 & 2.448 & 0.088 & 0.617 \\
SFFD & 0.823 & 0.253 & 10.586 & $0.001^{* *}$ & 2.278 \\
(SOP) & & & & & \\
TDER & 0.400 & 0.191 & 4.414 & $0.036^{*}$ & 1.492 \\
Constant & -0.771 & 0.830 & 0.861 & 0.353 & 0.463 \\
\hline
\end{tabular}

$* p<0.05$

$* * p<0.01$

Table 8 Predictive accuracy-Logistic regression

\begin{tabular}{llll}
\hline Logistics regression & \multicolumn{2}{l}{ Predicted by this study } & Accuracy $(\%)$ \\
\cline { 2 - 3 } & Accredited & Non-accredited & \\
\hline Actual IEQAS & & 18 & $76.6(\mathbf{5 9} / 77)$ \\
Accredited $(n=77)$ & $\mathbf{5 9}$ & $\mathbf{3 8}$ & $62.3(\mathbf{3 8} / 61)$ \\
$\begin{array}{c}\text { Non-accredited } \\
(n=61)\end{array}$ & 23 & & $70.3(\mathbf{9 7 / 1 3 8 )}$ \\
$\quad \begin{array}{l}\text { Overall }(N=138) \\
\end{array}$ & $\mathbf{9 7}$ & & \\
\hline
\end{tabular}

different HEI groups. As for TDER, the mean value by $T$ test indicates 2.943 and 3.175 for ACC and NAC institutions, respectively. From the non-parametric test, the remaining three factors-STES, SFFD, and TDER-are commonly significant at the 0.05 level. Hence, these four dichotomous variables were entered into the following three analyses in a discrete model.

\section{Logistic regression}

As a first discrete analysis method, we ran binary logistic regression on the SPSS software to predict the IEQAS outcomes based on values of the four key predictor variables (i.e., EDCS, STES, SFFD, and TDER). Tables 6, 7, and 8 present the empirical results for the LR method using the full sample data of 138 HEIs. As Table 6 shows, the log likelihood and the adjusted pseudo-R-square (Nagelkerke $R^{2}$ ) in the model become statistically meaningful with a considerable chi-square value at the level of significance, indicating that the LR-based discrete analysis may provide about $22 \%$ explanatory power to predict an outcome based on values of a set of the four input variables accordingly.

Concerning variables in the equation in line with the logit regression in Table 7, we can see that each coefficient $(B)$ for EDCS, SFFD, and TDER - used to estimate the log-odds ratios for each of the input variables-along with its associated standard error and Wald statistic —obtains significance, showing the correct sign. The Wald statistics suggest that SFFD is the most important factor along which ACC and NAC HEIs may be differentiated. However, it appears that STES is insignificant in terms of its ability to distinguish between the two groups. We, thus, report that three indices, excluding STES, mainly affect the predicted possibilities. Odds ratios [i.e., $\exp (B)$ for the predictors] are the exponentiation of the coefficients, estimating the risk of input factors. In the logistic regression, where its model is non-linear in an S-shape curve, we can interpret odds ratios shown on the SPSS variables in the equation table (or marginal effects for Stata ${ }^{\circledR / S A S}{ }^{\circledR}$ ), ceteris paribus (Kim \& Jeong, 2018; J. W. Ko, 2017). For every one-unit increase in EDCS score, we expect a 0.558 change in its odds ratio. Because the ratio is significantly less than 1.0 and its coefficient sign is negative, this case implies that the larger EDCS we get, the lower the IEQAS non-accreditation we predict. As we have the greater SFFD by a unit in odds ratio, we see the higher probable for the IEQAS accreditation by expecting a $2.278 \exp (B)$ change. Likewise, the same interpretation logic applies to TDER. ${ }^{4}$ Of three significant input factors, SFFD is the most influential variable in the model.

The LR statistics highlighted in a modified confusion matrix, shown in Table 8, explain that the overall predictive accuracy of the model is $70.3 \%$, where the accuracy is dependent on the type of accreditation. While the LR model seems to have correctly predicted over $76 \%$ of ACC institutes, it correctly predicts over $62 \%$ of NAC institutes.

\section{Discriminant analysis}

As a second binary statistical analysis, we performed linear DA. As a reminder, the predictor variables in DA, unlike LR, have a multivariate normal distribution, and the DA model is made of a discriminant function based on linear combinations of the variables between the two HEI groups. Table 9 shows that the canonical discriminant function has an Eigenvalue of 0.173 , and the canonical correlation coefficient for

\footnotetext{
4 The TDER-related result can be inferred that, unlike insolvent business firms, financially sound school foundations may show a high level of TDER; the Korean MoE reports that many leading private universities with an aggressive investment plan have shown a higher TDER on occasion than the other universities (National Assembly Budget Office, 2018).
} 
Table 9 Model summary-Discriminant analysis

\begin{tabular}{llllll}
\hline $\begin{array}{l}\text { Eigen- } \\
\text { value }\end{array}$ & $\begin{array}{l}\text { Coeffi- } \\
\text { cient }\end{array}$ & $\begin{array}{l}\text { Wilks' } \\
\text { lambda }\end{array}$ & $\begin{array}{l}\text { Chi- } \\
\text { square }\end{array}$ & $\begin{array}{l}\text { Degree of } \\
\text { freedom }\end{array}$ & $p$-value \\
\hline 0.173 & 0.384 & 0.853 & 21.459 & 3 & 0.000 \\
\hline
\end{tabular}

statistical skills, both EDCS and STES primarily relate to the prediction of IEQAS accreditation.

The DA statistics shown in Table 11 suggest that the overall prediction accuracy is a modest $66.7 \%$, which is lower than that reported by the former LR model (70.3\%). This DA
Table 10 Statistics in the classification-Discriminant analysis

\begin{tabular}{llllll}
\hline Input factors & accredited $(\mathrm{M})$ & $\begin{array}{l}\text { non-accredited } \\
(\mathrm{M})\end{array}$ & Wilks' lambda & $F$-value & $p$-value \\
\hline (EIV) & & & & & \\
EDCS & 3.249 & 2.743 & 0.943 & 8.287 & $0.005^{* *}$ \\
STES & 3.225 & 2.760 & 0.951 & 7.011 & $0.009^{* *}$ \\
SFFD & 2.940 & 3.170 & 0.986 & 1.913 & 0.169 \\
(SOP) & & & & 1.743 & 0.189 \\
TDER & 2.943 & 3.175 & 0.987 & & \\
\hline
\end{tabular}

$* p<0.05$

$* * p<0.01$

Table 11 Predictive accuracy-Discriminant analysis

\begin{tabular}{llll}
\hline Discriminant analysis & \multicolumn{2}{l}{ Predicted by this study } & Accuracy (\%) \\
\cline { 2 - 3 } & Accredited & Non-accredited & \\
\hline Actual IEQAS & & 20 & $74.0(\mathbf{5 7} / 77)$ \\
Accredited $(n=77)$ & $\mathbf{5 7}$ & $\mathbf{3 5}$ & $57.4(\mathbf{3 5} / 61)$ \\
$\begin{array}{c}\text { Non-accredited } \\
(n=61)\end{array}$ & 26 & & $66.7(\mathbf{9 2} / 138)$ \\
Overall $(N=138)$ & $\mathbf{9 2}$ & & \\
\hline
\end{tabular}

also correctly predicted $74.0 \%$ of the ACC HEIs as well as $57.4 \%$ of the NAC HEIs. We identify that the result is consistent with the finding that the chi-square statistic in the DA model appears lower than the LR's chi-square value. Each of the predictive accuracies made by DA has a relatively low level against the prediction accuracy in the LR model; there is a clear gap in NAC HEIs between LR (62.3\%) and DA $(57.4 \%)$, in particular.
Table 12 Case processing and variable importance-Neural network

\begin{tabular}{lcllllc}
\hline Input case & Processed & Assigned $(\%)$ & \multicolumn{2}{l}{ Input layer } & Importance & Normalized (\%) \\
\hline Training & 89 & 66.9 & (EIV) & EDCS & 0.241 & 100.0 \\
Testing & 44 & 33.1 & & STES & 0.231 & 95.9 \\
Valid & 133 & 100.0 & & SFFD & 0.168 & 69.8 \\
Excluded & 5 & - & (SOP) & TDER & 0.217 & 89.8 \\
\hline
\end{tabular}

the DA model is 0.384 . The model is thus significant at the 0.000 level based on Wilks' lambda statistic of 0.853 . Given that the DA model's chi-square statistic (24.775, see Table 6) is greater than that of LR (21.459), the explanatory power of this model is relatively smaller between the two discrete methods.

Table 10 presents the summary statistic in the classification of the DA model developed by all of the normalized four input variables. By considering $F$ - and $p$-values in the model, the most important factor is EDCS. The second most important factor is STES; however, SFFD appears statistically insignificant, and this result is inconsistent with that of the previous analysis (see Table 7). Within the two binary

\section{Multilayer perceptron (neural network)}

The third technique used within the study is the MLP. An MLP network should be trained first to estimate the synaptic weights and optimize the algorithm (IBM, 2019). Through the MLP procedure, training data are used to train the network, and testing data, along with a smaller sample size than that of training, are assigned to track errors identified during the training phase and to prevent overtraining. For this research shown in Table 12, 133 valid cases were assigned by a default setting as an optimal proportion (e.g., 2/3:1/3) during data processing in SPSS. As a result, 89 cases for 
Table 13 Predictive accuracy-Neural network by the MLP using the training sample

\begin{tabular}{llcl}
\hline Neural network & \multicolumn{2}{l}{$\begin{array}{l}\text { Predicted by this study- } \\
\text { Training }\end{array}$} & Accuracy (\%) \\
\cline { 2 - 3 } & Accredited & Non-accredited & \\
\hline Actual IEQAS & & 2 & $95.7(\mathbf{4 5} / 47)$ \\
Accredited $(n=47)$ & $\mathbf{4 5}$ & $\mathbf{2 2}$ & $52.4(\mathbf{2 2} / 42)$ \\
$\begin{array}{c}\text { Non-accredited } \\
(n=42)\end{array}$ & 20 & & $75.3(\mathbf{6 7 / 8 9})$ \\
Overall $(N=89)$ & $\mathbf{6 7}$ & & \\
\hline
\end{tabular}

Table 14 Predictive accuracy-Neural network by the MLP using the testing sample

\begin{tabular}{llll}
\hline Neural network & \multicolumn{2}{l}{$\begin{array}{l}\text { Predicted by this study- } \\
\text { Testing }\end{array}$} & Accuracy (\%) \\
\cline { 2 - 3 } & Accredited & Non-accredited & \\
\hline Actual IEQAS & & & $88.0(\mathbf{2 2} / 25)$ \\
Accredited $(n=25)$ & $\mathbf{2 2}$ & 3 & $47.4(\mathbf{9 / 1 9})$ \\
$\begin{array}{c}\text { Non-accredited } \\
(n=19)\end{array}$ & 10 & $\mathbf{9}$ & $70.5(\mathbf{3 1} / 44)$ \\
$\begin{array}{l}\text { Overall }(N=44) \\
\text { N }\end{array}$ & $\mathbf{3 1}$ & & \\
\hline
\end{tabular}

training and 44 cases for testing were automatically loaded due to a system-missing value in five cases. Together with the 133 cases, an internal sensitivity analysis was then made to compute the importance of each predictor in determining the MLP. As a result, the normalized importance demonstrates that EDCS appears the most important, and STES is the second most important, followed by SFFD in education investment and TDER within school operations, according to the figures.

Two confusion matrices in both Tables 13 and 14 report the predictive statistics obtained from the valid 133 HEI data using the MLP; the statistics show that each of the overall predictive accuracies from the training cases (using 89 HEI data) is $75.3 \%$ and from the testing cases (using 44 HEI data) is $70.5 \%$. In particular, both results appear to show that the prediction accuracies are very high for ACC HEIs (LR: 76.6\%; DA: 74.0\%; NN-MLP: 95.7\% and $88.0 \%$ ) as well as low for NAC HEIs (LR: $62.3 \%$; DA: $57.4 \%$; NN-MLP: $52.4 \%$ and $47.4 \%$ ); the NN outputs based on the MLP seem to have performed well for predicting ACC HEI groups. From the conservative perspective, we estimate that the NN's predictive accuracy is slightly higher than that of LR and noticeably higher than the DA's result.
Table 15 A summary of the highlighted findings for discussion

\begin{tabular}{llll}
\hline $\begin{array}{l}\text { Overall predictive accuracy across three analytic } \\
\text { techniques }\end{array}$ & $\begin{array}{l}\text { Important pre- } \\
\text { dictors }\end{array}$ & \\
\cline { 1 - 3 } $\begin{array}{l}\text { Logistic regres- } \\
\text { sion }\end{array}$ & $\begin{array}{l}\text { Discri- } \\
\text { minant } \\
\text { analysis }\end{array}$ & Neural network & \\
\hline $70.3 \%$ & $66.7 \%$ & $75.3 \%$ by training & EDCS (3) \\
& & $\begin{array}{l}70.5 \% \text { by testing } \\
\text { STES (2) }\end{array}$ & TDER (2) \\
EDCS & EDCS & EDCS & \\
SFFD & STES & STES & \\
TDER & & TDER & \\
\hline
\end{tabular}

Based on the results from descriptive statistics for the 138 Korean private HEIs, the key foci on the non-accredited institutions in IEQAS are also whether the universities are located in the provincial cities or the rural areas, which were particularly established in 1991-2020, having less than 200 departments and less than 500 international students

\section{Discussion and recommendations}

As we have demonstrated, our study mapped out an alternative model for the IEQAS using public disclosure data and examined the method of whether we might utilize it to predict a binary outcome of IEQAS accreditation; using the techniques, the time and effort gain may be an advantage for individuals who may have a concern about the specific Korean HEIs' accreditation. Based on the statistical findings of the $U$ test and $T$ test as well as the subsequent empirical results from three discrete analytic methods using a set of 138-HEI disclosed data, which were publicly available on the Korean government websites, we start a critical argument. To recap, we provide a highlighted summary first, as shown in Table 15, and answer the given research questions. Next, we continue a general discussion on the usefulness and contributions of this study, followed by the limitation and future research.

First, with the binary choice model, we are able to predict the outcomes of IEQAS accreditation in accuracy ranging from $66.7 \%$ to $75.3 \%$. In other words, within a possible error rate, the extent $(24.7 \% \sim 33.3 \%)$ is lower than that of the former studies (showing 31.5\% 37.0\% on average). In particular, the MLP reduces the error level up to the mid-20s in percentages, and the NN method is thus suited to predict the IEQAS accreditation. This result is consistent with the reports of prior studies in business management and hospitality, where it is claimed that NN outperforms statistical skills; the high predictive accuracy of NN is induced by its ability to build on the non-linearities and interactions among the assigned variables (Heazlewood et al., 2016; Spear \& Leis, 1996). Even in this study, the predictive accuracy using the intelligent computational skill also appears higher than 
those reported using the two traditional statistical methods. Furthermore, the synthetic results from a series of examinations explain that the most important index in this study that predicts the IEQAS accreditation is commonly EDCS in the education investment category. Specifically, by referring to Tables 4, 5, 7, 10, and 12, we reveal that the statistics related to EDCS in education investment are the most significant with each of the corresponding values. In predicting the IEQAS accreditation, STES in education investment and TDER within school operations are identified as the second most important indices as well across the three analytic techniques, while SFFD in education investment is ruled out as a key factor during the tests; we exclude it because only LR ensured that the index would be an important predictor, although its $p$-value in the LR coefficients is highly significant, showing a strong Wald statistic value (see Table 7). This judgment is primarily based on securing causality and generalizability across the three analyses.

Second, the most important predictor appears to be EDCS. By referring to the outputs from the $T$ test together (see Table 5), the factor indicates that its mean for ACC HEIs as 3.249 and for NAC HEIs as 2.743. As for TDER and STES, the mean value of each of the predictors shows that TDER's ACC HEIs is 2.943 and its NAC HEIs is 3.175, and ACC HEIs on mean for STES is 3.225 and NAC HEIs on STES' mean is 2.760 . Practically, we can explain the meaning of the figures that when assuming a certain HEI's EDCS as 3.4, it is predicted by the MLP that the institute may obtain the IEQAS accreditation at a probability of $70 \sim 75 \%$. In a similar vein, in the case of an institute indicating, for instance, 2.9 of TDER and 2.8 of STES, the HEI's IEQAS may be non-accredited at a probability of slightly more than $70 \%$. According to the findings from this study, when knowing a specific HEI's EDCS, STES, and TDER over the past years, anyone would be able to roughly predict the possibility of passing the IEQAS in the coming year. Overall, the discrete analysis model turned out to be effective; it may be applicable to predict a binary outcome of other HEI-related accreditations and expandable for a similar self-study to examine cross-border qualifications. This study also implies that, in the binary choice model, $\mathrm{NN}$ increases causality and multiple discrete skills raise generalizability.

As a whole, this study may answer the research questions that the alternative method using the MoE's public disclosure data on the Korean private HEIs is appealing and also capable of offering a reliable result to predict the outcomes of IEQAS accreditation. Adopting a neural network skill among three discrete techniques would be particularly recommendable, while education cost per student, tuition for education services, and total debt-to-equity ratio may be worth noting among nine competitiveness indices. It is known that a self-study method can be supplementary to prepare the national accreditation internally within an HEI before the critical national QA process, and the practice will be in favor using diverse information from a variety of public sources (Ingvarson et al., 2006; Leeh, 2015). In that sense, we recommend from the literature and our findings that the Korean government should open more IEQAS-related quantitative and qualitative disclosure information on the Korean HEIs to encourage higher education researchers to develop further reliable self-study instruments for individuals and a professional self-evaluation against the IEQAS accreditation.

This study has multiple implications for Korean and international higher education. The first implication is that a national/international QA accreditation outcome in a binary setting can be predictable by a dataset available to the public. Also, in practice, an application of the MLP possibly increases internal validity, and a binary choice model incorporating multiple discrete skills can also improve external reliability. In addition, this study demonstrates the usability of the publicly-available data for a regular, informal selfstudy process in preparing the national accreditations at the school/personal level. By leveraging the disclosed data set, not only managers with HEIs but also influential stakeholders can produce reliable results with the expenditure of minimal time and effort. Lastly, for more contributions to developing conceptual knowledge in QA accreditation, higher education scholars and practitioners might seek whether there would be other indicators with a stronger correlation with the results of accreditation.

\section{Contributions}

Many HEIs in the world have been challenged by accreditation issues in providing a good-quality learning environment for international students (Hou et al., 2016). For instance, in achieving the high standards recognized by international accrediting bodies, most HEIs and business schools are under international pressures from the intensified quality assessment processes and cross-border accreditations, such as the European Quality Improvement System and the US-based AACSB (Van Acker et al., 2014) that are focusing on the goal of studying, even though the IEQAS does not belong to the same category. Under this cumbersome accreditation system, the time and effort in finding the right analytic methods and collecting relevant data for predicting a national accreditation system's outcomes gain used in this study may be an advantage for individuals. Our contributions will enable them to prepare for accreditation by way of a casual self-study covering both empirical and conceptual domains. First, this work has value as empirical research that applies business management to the field of higher education. In general, a discrete analytic method has been used in business-related studies for solving a variety of operational 
or financial problems. With a pragmatic approach and interdisciplinary view, we introduced the binary choice model employed for a firm's assessment to the prediction of outcomes of a national accreditation system. This approach would be of value to higher education practitioners and senior administrators with institutions. Multiple evidence presenting the empirical results for three analytic methods in this study might also be useful for their related quantitative studies. Second, we have made a conceptual contribution to higher education academia. Transforming a binary statistical choice method to a combined binary choice method incorporating the MLP within a threefold discrete model was a conceptually new attempt to predict the IEQAS accreditation in an either-or result. In addition, the approach enabled this research to secure a high prediction accuracy as well as to generate external reliability. At large, this research will contribute to the body of practical knowledge about the use of different analytic methods by filling the gap in predicting a specific national QA accreditation using public disclosure data within HEIs.

\section{Limitation and future research}

There were three main limitations to this study in relation to the literature on international higher education and the range of data that the Korean MoE provides. First, in the aspect of the NN statistical technique, we had few references for comparing our findings with those of the HEI-related literature. Therefore, predicting the probability of responses to other HEI accreditation systems and discussing the ability of our binary choice models with the MLP as well as the prediction accuracy by the network were unavoidably limited. Second, the period of disclosed datasets and the scope of the secondary data might be a potential issue. In the study, we should rely on the government data, even only for the Korean "private" institutions, produced over a 3-year span, as the government-established HEIs are under no legal obligation to be publicly transparent about their operational status. Moreover, the disclosed data we manipulated did not contain particular elements presenting the quality of academic programs for students from overseas. Last, in a part of employing three analytic skills, this study utilized LR statistics. In the logistic regression, where its model structure is in a non-linear S-curve, marginal effects or odds ratio should be properly discussed. Because specializing in IBM SPSS Statistics, these researchers alternatively provided odds ratio [i.e., $\exp (B)]$ and the related interpretation, not utilizing the statistical packages that present the values of marginal effects.

In the era of big data, social science researchers are provided with plentiful secondary data sources and open-reference meta-data containing other forms of meaningful information about data. In this regard, future research may require a focus on three perspectives: a set of longer time-series data and more internationalized in nature. For instance, we will be able to obtain disclosure data from the operators of The Times Higher Education World University Rankings or QS World University Rankings. Such sources cover the Korean national HEIs, provide researchers and practitioners with a historical dataset that has been accumulated over 10 years, and offer diverse elements related to every single HEI's performance and educational quality on an international level. Then, our future work can also compare to baseline models whether, for example, this year's IEQAS accreditation outcome will appear to be the same as last year's outcome and will be able to judge how accurate the prediction for each year will be.

\section{Conclusion}

In most countries, national accreditation is an indispensable part of the institutional system for general universities and junior colleges. However, accreditation systems on a national level in assessing HEIs may be criticized for many complex indicators in evaluating each institute's quality assurance arrangements, as the Korean IEQAS has been. Predicting the outcomes of national accreditation systems is thus meaningful in allowing internal and external stakeholders to easily access reliable disclosed data and quickly generate the prediction accuracy as high as possible. By utilizing traditional statistical skills and intelligent computational methods, we can increase internal validity and ensure external reliability across various analytic techniques. In conjunction with reliable secondary data arrangements, an exemplar self-study demonstrated within this work will be helpful to develop more advanced models. Similarly, our pragmatic approach can also be applied to predict a binary result of similar HEIrelated QA accreditation and expanded to an informal selfreflection to forecast cross-border qualifications.

Acknowledgements The authors gratefully acknowledge the faculty members of the Business Information Systems at Auckland University of Technology as well as Professor Stephen MacDonell with Otago University, New Zealand, for their valuable insights and useful comments in the improvement of this paper.

Author contributions Two authors contributed to overall research phases ranging from an initial conceptual design to the last modifications after third-party proofreading. In particular, Dr Lee was more focusing on coding/analyzing data, while Associate Professor Cho was primarily collecting online data related to this study. Both authors inspected and approved the final manuscript before the submission to Asia Pacific Education Review in December 2020.

Funding This research received no specific grant from any funding agency in the public, commercial, or not-for-profit sectors.

Data availability My University Competitiveness-Academy Information|Public Disclosure Information: www.academyinfo.go. 
kr/pubinfo/pubinfo0360/selectListLink.do. The 2019 IEQAS Certified schools-Study in Korealrun by Korean Government: www.study inkorea.go.kr/ko/sub/college_info/certified_intro.do. The 2019 IEQAS Review-the Ministry of Justice: www.moj.go.kr/bbs/immigration/ 211/488960/artclView.do.

Code availability Eight.sav coded files formatted in IBM SPSS 26.

\section{Declarations}

Conflict of interest Not applicable.

Open Access This article is licensed under a Creative Commons Attribution 4.0 International License, which permits use, sharing, adaptation, distribution and reproduction in any medium or format, as long as you give appropriate credit to the original author(s) and the source, provide a link to the Creative Commons licence, and indicate if changes were made. The images or other third party material in this article are included in the article's Creative Commons licence, unless indicated otherwise in a credit line to the material. If material is not included in the article's Creative Commons licence and your intended use is not permitted by statutory regulation or exceeds the permitted use, you will need to obtain permission directly from the copyright holder. To view a copy of this licence, visit http://creativecommons.org/licenses/by/4.0/.

\section{References}

Bae, S. H. (2015). An analysis on the international student recruitment and management policies in South Korea. International Journal of Education and Research, 3(9), 331-342. http://www.ijern.com/ journal/2015/September-2015/26.pdf

Bitter, M. E., \& Henry, L. J. (2015). Accounting administrator perceptions of impediments to seeking AACSB accounting accreditation. The Accounting Educator Journal, 25, 39-66. http://aejournal.com/ojs/ index.php/aej/article/view/274

Choi, J. I., \& Moon, M. J. (2017). University responses to the universities reorganization evaluation policy. The Korean Journal of Local Government Studies, 21(2), 305-323. https://doi.org/10.20484/klog. 21.2.13

Cochran, W. G. (1977). Sampling Techniques (3rd ed.). Wiley.

Galbraith, C. S., Merrill, G. B., \& Kline, D. M. (2012). Are student evaluations of teaching effectiveness valid for measuring student learning outcomes in business related classes? A neural network and Bayesian analyses. Research in Higher Education, 53, 353-374. https://doi.org/ 10.1007/s11162-011-9229-0

Heazlewood, I., Walsh, J., Climstein, M., Kettunen, J., Adams, K., \& DeBeliso, M. (2016). A comparison of classification accuracy for gender using neural networks multilayer perceptron (MLP), radial basis function $(\mathrm{RBF})$ procedures compared to discriminant function analysis and logistic regression based on nine sports psychological constructs to measure motivations to participate in Masters Sports competing at the 2009 World Masters Games. In P. Chung, A. Soltoggio, C. Dawson, Q. Meng, \& M. Pain (Eds.), Proceedings of the 10th International Symposium on Computer Science in Sports (ISCSS). Advances in intelligent systems and computing 392. Springer.

Hou, Y. C., Ince, M., Tsai, S., Wang, W., Hung, V., Jiang, C. L., \& Chen, K. H. J. (2016). Quality assurance of joint degree programs from the perspective of quality assurance agencies: Experience in East Asia. Higher Education Research \& Development, 35(3), 473-487. https:// doi.org/10.1080/07294360.2015.1107878

Hughes, C., \& Barrie, S. (2010). Influences on the assessment of graduate attributes in higher education. Assessment \& Evaluation in Higher
Education, 35(3), 325-334. https://doi.org/10.1080/0260293090 3221485

IBM (2019). IBM SPSS Statistics 26 Documentation. IBM Corp. Retrieved from https://www.ibm.com/support/pages/ibm-spssstatistics-26documentation

Ingvarson, L., Elliott, A., Kleinhenz, E., \& McKenzie, P. (2006). Teacher education accreditation: A review of national/international trends and practices. Teacher Education, 1. Retrieved fromhttps://research.acer. edu.au/cgi/viewcontent.cgi?article $=1000 \&$ context=teacher_educa tion

Kim, J. B., \& Oh, S. S. (2015). A pathway of knowledge transfer from Korea to Asian countries. After-development dynamics: South Korea's contemporary engagement with Asia, 201. https://doi.org/ 10.1093/acprof:oso/9780198729433.003.0011

Kim, S., \& Jeong, G. (2018). An analysis for influencing factors in purchasing electric vehicle using a binomial logistic regression model. Journal of the Korean Society of Civil Engineers, 38(6), 887-894. https://doi.org/10.12652/Ksce.2018.38.6.0887

Kim, U., \& Lee, J. (2017). A study on a performance analysis of the international education quality assurance system: Focusing on the difference between certified and uncertified universities. CNU Journal of Educational Studies, 38(1), 295-315. https://doi.org/10.18612/ cnujes.2017.38.1.295

Ko, J. W. (2017). Quality assurance system in Korean higher education: Development and Challenges. In M. Shah, \& T.N.D. Quyen, (Eds.), The Rise of Quality Assurance in Asian Higher Education, 109-125. ProQuest Ebook Central. http://ebookcentral.proquest.com/lib/aut/ detail.action?docID $=4866436$

Ko, K. (2017). Use of logistic regression analysis in the field of public administration. Modern Society and Public Administration, 12, 3-33. https://doi.org/10.26847/mspa.2017.27.4.3

Leeh, J. K. (2015). A Comparative Study of Instruments Used in the Quality Assurance for Internationalization of Higher Education. Asia-Pacific Collaborative education Journal, 11(1), 57-78. https:// www.academia.edu/download/38770616/Indonesian_Students_Multi cultural_Awareness.pdf\#page $=61$

Mills, R. J., Velasquez, N. F., Fadel, K. J., \& Corbin, C. (2012). Examining IS curriculum profiles and the IS 2010 model curriculum guidelines in AACSB accredited schools. Journal of Information Systems Education, 23(4), 417-428. http://jise.org/Volume23/n4/JISEv23n4p 417.pdf

National Assembly Budget Office (2018). Fiscal Year 2017: The Board of Education (2018-II), National Assembly of South Korea. https:// www.nabo.go.kr/Sub/01Report/01_01_Board.jsp?bid=19\&item_id= $6650 \&$ arg_id $=6650 \&$ funcSUB $=$ view

Oh, E. J. (2016). Analysis of information disclosure system of higher education. Asia-Pacific Journal of Multimedia Services Convergent with Art, Humanities, and Sociology, 6(3), 363-372. https://doi.org/10. 14257/AJMAHS.2016.03.41

Oh, Y. J., \& Park, M. A. (2018). The role of international education quality assurance system (IEQAS) and its implications. Global Studies Education, 10(3), 139-164. https://doi.org/10.19037/agse.10.3.05

Paik, S. J. (2015). Policies to attract high quality foreign students into Korea. KDI school working paper series no. 15-10. KDI School of Public Policy and Management, 1, 11-12. https://archives.kdischool. ac.kr/bitstream/11125/29449/1/WP2015-10.pdf

Shah, M. (2012). Ten years of external quality audit in Australia: Evaluating its effectiveness and success. Assessment \& Evaluation in Higher Education, 37(6), 761-772. https://doi.org/10.1080/02602938.2011. 572154

Sin, C., Tavares, O., \& Amaral, A. (2017). The impact of programme accreditation on Portuguese higher education provision. Assessment \& Evaluation in Higher Education, 42(6), 860-871. https://doi.org/ $10.1080 / 02602938.2016 .1203860$ 
Sohn. S. J. (2013). Evaluation of Korean Business Program Accreditation and future directions. Korean Business Education Review, 28(6), 129-153. http://uci.or.kr/G704001274.2013.28.6.002

Spear, N. A., \& Leis, M. (1996). A comparison of the classification and the predictive accuracy of artificial neural networks, logit models and multiple discriminant analysis: A study of the accounting method choice by oil and gas producers. University of Melbourne.

StudyinKorea (2021, May 18). Introduction of IEQAS - International Education Quality Assurance System. https://www.studyinkorea.go.kr/en/ sub/college_info/certified_intro.do

Van Acker, L., Bailey, J., Wilson, K., \& French, E. (2014). Capping them off! Exploring and explaining the patterns in undergraduate capstone subjects in Australian business schools. Higher Education Research
\& Development, 33(5), 1049-1062. https://doi.org/10.1080/07294 360.2014 .890567

Walters, C. (2020). The complexity of leadership in South African universities. Higher Education Research \& Development. https://doi.org/ 10.1080/07294360.2020.1811644

Wolff, R. A. (1993). The accreditation of Higher Education Institutions in the United States. Higher Education in Europe, 18(3), 91-99. https:// doi.org/10.1080/0379772930180311

Publisher's Note Springer Nature remains neutral with regard to jurisdictional claims in published maps and institutional affiliations. 